\title{
Oncogenic p95HER2/611CTF primes human breast epithelial cells for metabolic stress-induced down-regulation of FLIP and activation of TRAIL-R/Caspase-8-dependent apoptosis
}

\author{
Rosa Martín-Pérez ${ }^{1,2,3}$, Rosario Yerbes ${ }^{1}$, Rocío Mora-Molina ${ }^{1}$, Ana Cano-González ${ }^{1}$, \\ Joaquín Arribas ${ }^{4,5,6,7}$, Massimiliano Mazzone ${ }^{2,3}$, Abelardo López-Rivas ${ }^{1,7}$ and \\ Carmen Palacios ${ }^{1}$ \\ ${ }^{1}$ Centro Andaluz de Biología Molecular y Medicina Regenerativa-CABIMER, CSIC-Universidad de Sevilla-Universidad Pablo de \\ Olavide, Sevilla, Spain \\ ${ }^{2}$ Lab of Tumor Inflammation and Angiogenesis, VIB, Leuven, Belgium \\ ${ }^{3}$ Lab of Tumor Inflammation and Angiogenesis, Department of Oncology, KU Leuven, Leuven, Belgium \\ ${ }^{4}$ Preclinical Research Program, Vall d'Hebron Institute of Oncology (VHIO), Barcelona, Spain \\ ${ }^{5}$ Department of Biochemistry and Molecular Biology, Universitat Autónoma de Barcelona, Campus de la UAB, Bellaterra, \\ Spain \\ ${ }^{6}$ Institució Catalana de Recerca i Estudis Avançats (ICREA), Barcelona, Spain \\ ${ }^{7}$ Centro de Investigación Biomédica en Red-Oncología (CIBERONC), Carlos III Health Institute, Madrid, Spain \\ Correspondence to: Carmen Palacios, email: carmen.palacios@cabimer.es \\ Abelardo López-Rivas, email: abelardo.lopez@cabimer.es
}

Keywords: $p 95 H E R 2 / 611 C T F$, metabolic stress, TRAIL-R, FLIP, mTOR

Received: January 10, $2017 \quad$ Accepted: September 16, $2017 \quad$ Published: October 03, 2017

Copyright: Martín-Pérez et al. This is an open-access article distributed under the terms of the Creative Commons Attribution License 3.0 (CC BY 3.0), which permits unrestricted use, distribution, and reproduction in any medium, provided the original author and source are credited.

\section{ABSTRACT}

Oncogenic transformation triggers reprogramming of cell metabolism, as part of the tumorigenic process. However, metabolic reprogramming may also increase the sensitivity of transformed cells to microenvironmental stress, at the early stages of tumor development. Herein, we show that transformation of human breast epithelial cells by the p95HER2/611CTF oncogene markedly sensitizes these cells to metabolic stress induced by the simultaneous inhibition of glucose and glutamine metabolism. In p95HER2/611CTF-transformed cells, metabolic stress activates a TNF related apoptosis-inducing ligand (TRAIL)-R and caspase-8-dependent apoptotic process that requires prior down-regulation of cellular FLICE-like inhibitor protein (C-FLIP) levels. Importantly, sustained mTOR activation is involved in FLIP down-regulation and apoptosis induced by metabolic stress. In vivo experiments in immunodeficient mice demonstrate a requirement for caspase-8 in restraining primary tumor growth of xenografts with p95HER2/611CTF-transformed cells. Collectively, these data define a critical role of the extrinsic pathway of apoptosis in the control of tumor initiation by microenvironmental cues.

\section{INTRODUCTION}

Amplification of a genomic region on chromosome 17q12 containing the HER2/ERBB2 gene, a member of the ERBB receptor family, has been observed in about $25 \%$ of breast tumors and this is associated with aggressive disease and lower survival of patients [1]. Despite the remarkable success of anti-HER2/ERBB2 therapies, patients with advanced HER2-positive breast cancer frequently display primary resistance [2]. Moreover, in patients initially sensitive to these agents, acquired resistance may emerge over time [2]. A potential mechanism of resistance to HER2/ERBB2-directed therapies is the expression of an amino terminally truncated form of HER2/ERBB2 known as p95HER2/611CTF generated by alternative initiation of translation [3]. This truncation leads to 
spontaneous homodimerization which results in a gainof-function compared with wild-type HER2/ERBB2 $[3,4]$. p95HER2/611CTF expression leads to deregulation of intracellular signalling pathways, such as the extracellular signal-regulated kinase (ERK) and the phosphoinositide-3-kinase (PI3K)/protein kinase B (AKT)/ mechanistic target of rapamycin (mTOR) pathways [5] that control cell metabolism, growth and proliferation. Clinically, patients with high-p95HER2/611CTF tumors had significantly worst outcome compared with those with low-p95HER2/611CTF tumors [5].

To survive the hostile environment of tumors a number of intracellular signalling pathways are activated in tumor cells, facilitating tumor growth [6]. Although an increased consumption of glucose through aerobic glycolysis is important to meet the increased energetic and biosynthetic demands of tumor cells [7], glutamine is also an essential nutrient to support cell survival and growth of many tumor cells [8]. Glutamine contributes substantially to maintain macromolecular synthesis, glutathione levels and bioenergetics of proliferating tumor cells [8]. Importantly, prior to metabolic adaptation, oncogenic transformation renders tumor cells initially sensitive to nutrient shortage, in particular to glucose and glutamine deprivation $[9,10]$. However, the molecular determinants controlling the cell death response of oncogene-transformed cells to nutrient deprivation remain to be identified.

The so-called extrinsic pathway of apoptosis utilises membrane-localized death receptors of the tumor necrosis factor (TNF) receptor superfamily to activate the caspases cascade and apoptosis upon ligand binding [11]. Activation of TRAIL receptors leads to the formation of a death-inducing signaling complex (DISC), which includes the receptor itself, the adapter molecule FADD and procaspase- 8 [12]. Processing and activation of caspase- 8 at the DISC leads to a cascade of apoptotic events which results in the death of the cell. At the DISC level, the apoptotic signal may be inhibited by cFLIP, the homologue of vFLIP in vertebrate cells [13]. Interestingly, in recent years there have been some reports on the involvement of TRAIL receptors in cell fate decisions after endoplasmic reticulum stress $[14,15]$. In addition, the induction of an integrated stress response by certain antitumor drugs triggers cell death in different tumor cells through the activation of TRAIL-R2/DR5-dependent apoptosis [16].

Here, we examined the impact of inhibiting both glycolysis and glutamine metabolism on the viability of human breast epithelial cells transformed by the p95HER2/611CTF oncogene. We found that metabolic stress induces TRAIL-R2/DR5 clustering at the plasma membrane and down-regulates FLIP expression, which leads to activation of a TRAIL-R/caspase-8-dependent apoptotic program in p95HER2/611CTF-transformed cells. Remarkably, when glycolysis is inhibited addiction of p95HER2/611CTF-transformed cells to glutamine relies on the sustained activation of mTOR complexes. In addition, in vivo experiments demonstrate a key role of caspase- 8 in the prevention of p95HER2/611CTFmediated tumor formation. Collectively, these results point to a role of the extrinsic apoptotic pathway in the control of tumor growth by microenvironmental factors.

\section{RESULTS}

\section{Expression of p95HER2/611CTF oncogene sensitizes human breast epithelial cells to metabolic stress-induced cell death through a TRAIL-R and caspase-8-dependent apoptotic pathway}

MCF10A cells, a non-transformed human mammary epithelial cell line, have been used as a model system to investigate the biological properties of oncogenes in tumor initiation and progression [17-19]. We have examined the impact of p95HER2/611CTF expression on the cellular response of MCF10A cells to metabolic stress. Inhibition of glucose metabolism with 2-deoxyglucose (2DG) concurrently with deprivation of glutamine markedly induced apoptosis in p95HER2/611CTF cells as compared to control cells or cells expressing wildtype HER2/ERBB2 (wt-HER2) (Figure 1A-1B). These observations were extended to the $184 \mathrm{~A} 1$ cell line, another immortalized, non-tumorigenic human breast epithelial cell line. We generated a bulk population of 184A1 cells transformed by retroviral infection with an empty vector (mock) or the p95HER2/611CTF-encoding vector. Initial studies with these cell lines demonstrated a lack of sensitivity of p95HER2-184A1 cells to starvation (Supplementary Figure 1A). Western blot analysis in the bulk population of p95HER2-184A1 cells revealed a markedly reduced HER2 expression as compared to p95HER2-MCF10A cells that may be relevant in the lack of sensitivity to starvation-induced apoptosis. To circumvent this problem we selected different clones from the bulk populations of mock and p95HER2 cells which were subsequently used to determine HER2 expression and their apoptotic response to starvation. Results shown in Supplementary Figure 1B demonstrate that whereas mock clones were resistant to starvation, metabolic stress activated an apoptotic process in the p95HER2 clones. In both cellular models, apoptosis was inhibited in the presence of the HER2/ERBB2 tyrosine kinase inhibitor lapatinib (Figure 1C, Supplementary Figure 1C), strongly supporting the hypothesis that sensitivity to metabolic stress results from the constitutive activation of p95HER2/611CTF tyrosine kinase.

Induction of the extrinsic apoptotic pathway by TRAIL receptor activation has been observed in cells undergoing endoplasmic reticulum (ER) stress [14, 15]. We next studied the role of the TRAIL system in the differential activation of apoptosis by the combination 
of 2DG and glutamine deprivation in p95HER2/611CTF cells. Compared to mock cells, p95HER2/611CTFtransformed cells expressed higher TRAIL-R2/DR5 levels at the cell surface (Supplementary Figure 2A, left panel) and consequently showed an increased sensitivity to exogenous TRAIL (Supplementary Figure 2A. right panel). Remarkably, metabolic stress induced caspase- 8 activation specifically in p95HER2/611CTF cells (Figure 2A), suggesting that differential activation of the extrinsic apoptotic pathway may underlie the increased sensitivity of these cells to metabolic stress.

Up-regulation of TRAIL-R2/DR5 expression following ER stress has been associated to activation of apoptosis in various cell types $[14,15]$. However, we did not observe an increase in either total (Supplementary Figure 2B) or surface (Supplementary Figure 2C) TRAIL-R2/DR5 levels following metabolic stress in p95HER2/611CTF-transformed cells. In contrast, treatment with thapsigargin, a potent inducer of ER stress, significantly enhanced plasma membrane levels of TRAIL-R2/DR5 (Supplementary Figure 2C). Likewise, expression levels of FADD and caspase-8, two key components of the death-inducing signaling complex (DISC) in the extrinsic apoptotic pathway, remained unaffected after metabolic stress (Supplementary Figure 2B). However, silencing caspase- 8 expression by RNA interference markedly inhibited metabolic stress-induced apoptosis in p95HER2/611CTF cells (Figure 2B, Supplementary Figure 3A). Furthermore, simultaneous knockdown of both TRAIL-R1/DR4 and TRAIL-R2/DR5 significantly reduced apoptosis upon metabolic stress (Figure 2B, Supplementary Figure 3B), suggesting a role of the TRAIL system in this cell death process. Importantly, silencing TRAIL expression by siRNA did not prevent apoptosis induced by 2DG in glutamine deprived-cells (Figure 2C) indicating that a

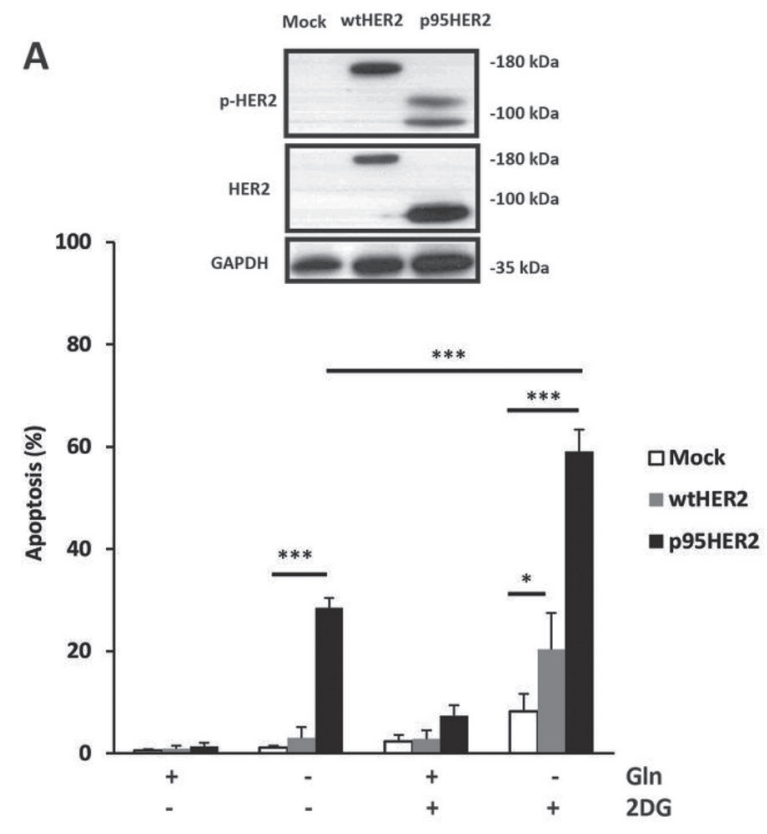

B
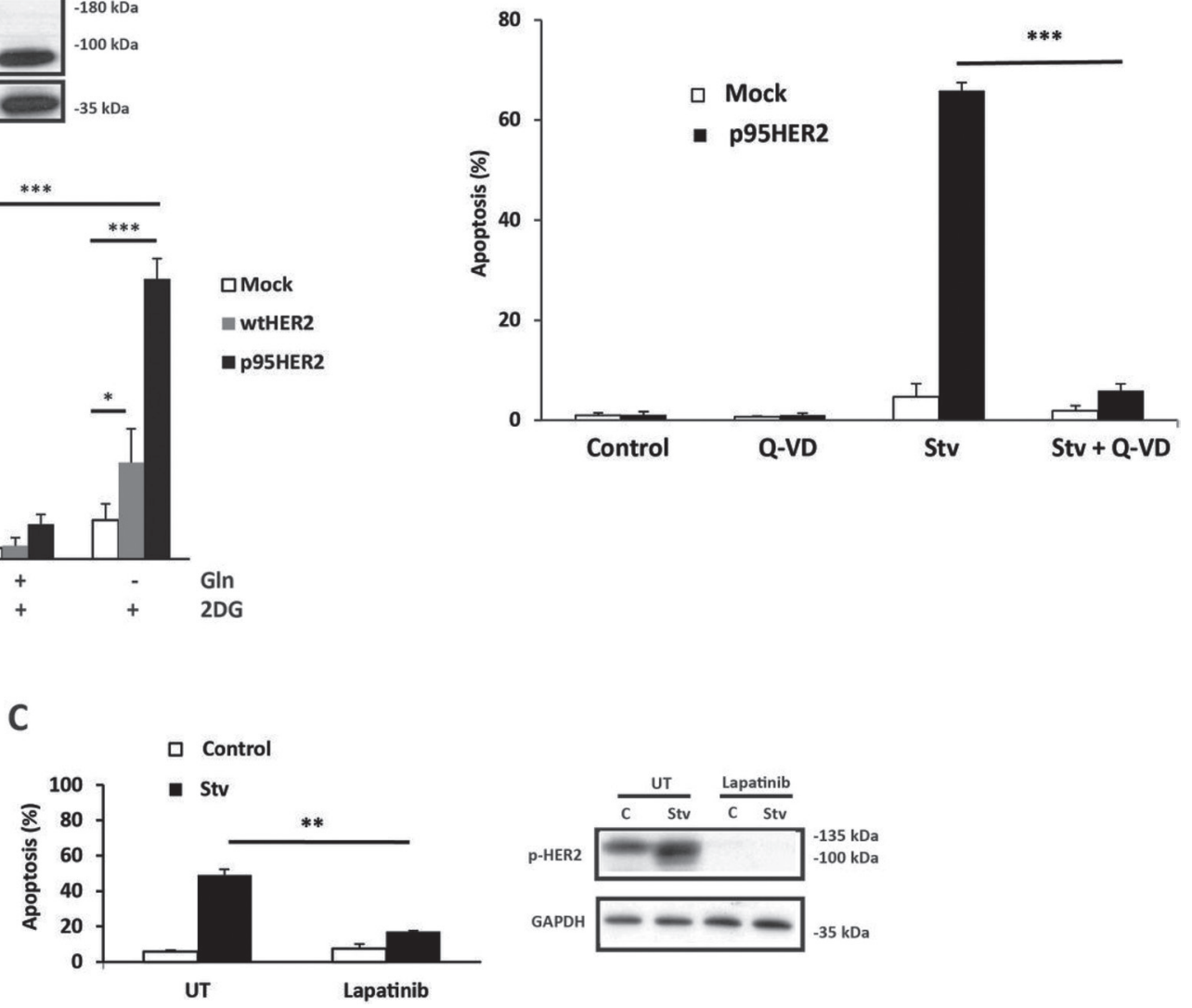

Figure 1: Increased sensitivity of p95HER2/611CTF-overexpressing cells to metabolic stress. (A) Cells were cultured for $30 \mathrm{~h}$ in medium containing the indicated additions and apoptosis was determined as described in Materials and Methods. Western blotting shows the expression of p-HER2 (Tyr1248) and total HER2. (B) Apoptosis in mock and p95HER2/611CTF cells incubated for $30 \mathrm{~h}$ either in complete or Stv medium (glutamine-free medium + $10 \mathrm{mM} 2 \mathrm{DG})$ in the presence or absence of Q-VD $(20 \mu \mathrm{M})$. (C) p95HER2/611CTF cells were incubated in control or Stv medium either in the presence or absence of Lapatinib $(5 \mu \mathrm{M})$, for $30 \mathrm{~h}$ to measure apoptosis (left panel) or for $16 \mathrm{~h}$ to analyze p-HER2 expression (right panel). Error bars, standard deviation (SD) from three independent experiments. $* * * P<0.001, * * P<0.01, * P<0.05$. 
ligand-independent mechanism of apoptosis through the extrinsic pathway was activated during metabolic stress, specifically in p95HER2/611CTF cells.

\section{Caspase-8 knockdown promotes tumor growth in a xenograft model of p95HER2/611CTF- expressing cells}

Nutrient deprivation is a common feature of rapidly growing tumors [20]. To translate our in vitro findings into an in vivo model of primary tumor growth we first knockeddown stably caspase- 8 expression in p95HER2/611CTFoverexpressing breast epithelial cells with shRNA by lentiviral infection and determined the apoptotic response of these cells to metabolic stress. As shown in Figure 3A, stable silencing of caspase- 8 expression markedly reduced the sensitivity of p95HER2/611CTF cells to metabolic stress, further confirming the results obtained with siRNA oligonucleotides (Figure 2B and Supplementary Figure 3A).

It has been shown that HER2/ERBB2 activation in MCF10A cells initiates a sequence of events that is characteristic of neoplastic progression in early-stage epithelial tumours [18]. In addition, expression of the p95HER2/611CTF oncogene promotes the development of aggressive and invasive mammary tumors in transgenic animals [5]. In this regard, p95HER2/611CTF-expressing MCF10A cells shows anchorage-independent growth in soft agar assays (Supplementary Figure 4A) and invasive growth in Matrigel (Supplementary Figure 4B), two hallmarks of cell transformation. To examine the role of the extrinsic apoptotic pathway in the tumoral behavior of p95HER2/611CTF-transformed cells in an in vivo setting we then injected control (Scr) or caspase-8silenced p95HER2/611CTF cells subcutaneously into SCID-beige mice. In agreement with the data about the anchorage-independent growth of p95HER2/611CTF cells, control cells gave rise to detectable tumors within 6 weeks of injection (Figure 3B). Strikingly, we observed that caspase- 8 knockdown clearly increased p95HER2/611CTF-mediated tumorigenicity. Thus, mice injected with caspase-8-silenced p95HER2/611CTF cells developed tumors with an increased volume (Figure 3B)
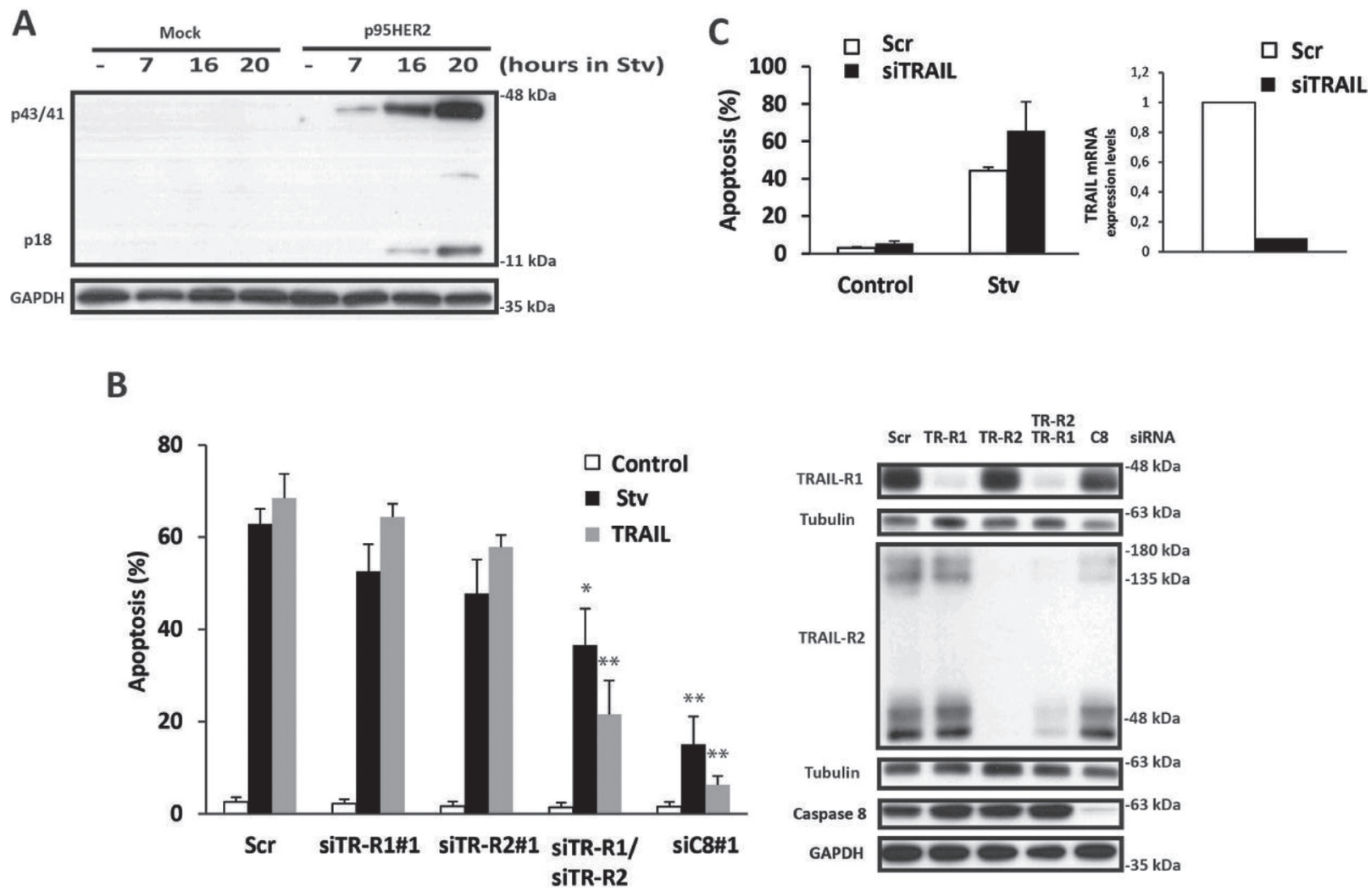

Figure 2: Role of the extrinsic pathway of apoptosis in metabolic stress-induced cell death. (A) Mock or p95HER2/611CTF cells were cultured in starvation medium for the indicated times. Following these treatments, caspase- 8 activation was assessed by western blotting. Results are representative of three independent experiments. (B) p95HER2/611CTF cells were transfected for $48 \mathrm{~h}$ either with a scrambled oligonucleotide (Scr) or with the indicated siRNAs targeting TRAIL-R1, TRAIL-R2, or Caspase-8. Cells were then cultured either in complete or Stv medium, or treated with soluble TRAIL $(50 \mathrm{ng} / \mathrm{mL})$ for $30 \mathrm{~h}$ and apoptosis was determined (left panel). Error bars, SD from three independent experiments. ${ }^{*} P<0.01,{ }^{*} P<0.05$. Protein knockdown was assesed by western blotting (right panel). (C) p95HER2/611CTF cells transfected with either a siRNA targeting TRAIL or a scrambled oligonucleotide were incubated for $30 \mathrm{~h}$ in complete or starvation medium and apoptosis was determined (left panel). Results show the average and range of two independent experiments. TRAIL knockdown was assessed by RT-qPCR (right panel) as described in Materials and Methods. 
and weight (Figure 3C) compared with the control group. These results were in line with our in vitro data on the key role of the extrinsic apoptotic pathway in the hypersensitivity of p95HER2/611CTF-transformed cells to metabolic stress. Our data suggest that prior to metabolic adaptation and tumor vessels formation, primary tumor development will be markedly dependent on nutrient availability in the tumor microenvironment which in turn controls the activity of the TRAIL-R/ caspase-8 system. Indeed, nuclei staining with Hoechst demonstrated the presence of fragmented nuclei in sections from control p95HER2/611CTFshScr tumors that were markedly reduced in p95HER2/611CTF-shCasp8 tumors (Figure 3D). These results suggested that caspase- 8 knockdown is instrumental to bypass cell death in line with the in vitro experiments. In addition, analysis of CD31 staining in tumor sections showed a significant increase in vessels formation in shCasp8 tumors as compared to shScr tumors (Figure 3D). Therefore, increased tumor growth in mice injected with p95HER2/611CTF-shCasp8 cells is likely inducing angiogenesis, thus overcoming their demand for oxygen and nutrient supply.

\section{p95HER2/611CTF expression promotes TRAIL-R2/DR5 clustering at the plasma membrane upon metabolic stress}

To cope with environmental or intrinsic stresses, mammalian cells induce an adaptive response through the activation of a family of eIF2 $\alpha$ protein kinases [21]. Upon eIF $2 \alpha$ phosphorylation global protein translation is inhibited to prevent aggravation of stress. To get further insight into the mechanism of metabolic stress-induced
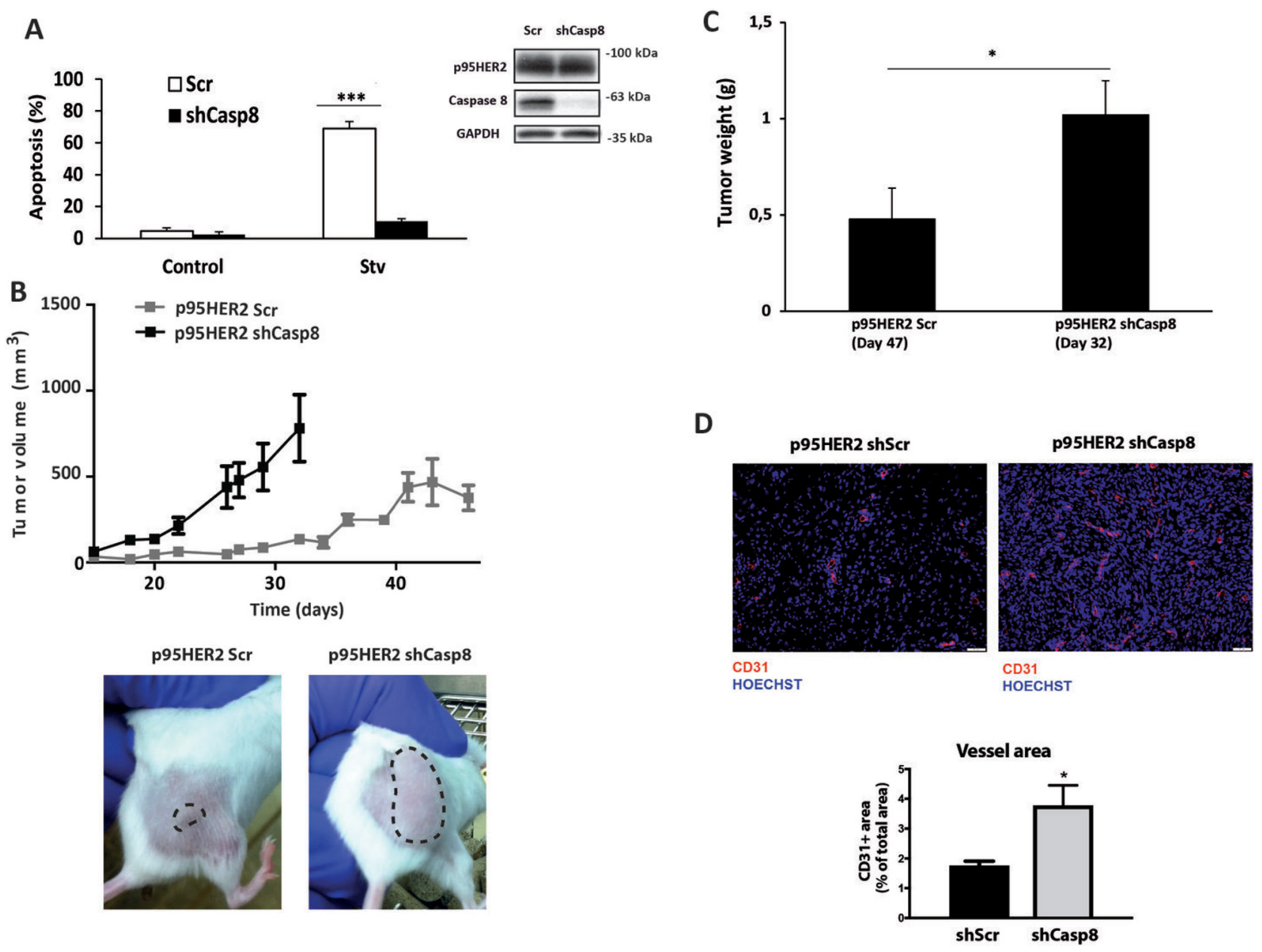

Figure 3: Caspase-8-dependent inhibition of tumor growth. (A) p95HER2/611CTF cells stably expressing a Scrambled or a Caspase 8-targeting shRNA were cultured either in complete or starvation medium and apoptosis was measured (left panel). Caspase-8 knockdown was determined by western blotting (right panel). Error bars, SD from three independent experiments. $* * * P<0.001$. (B) Subcutaneous growth of p95HER2/611CTF cells stably expressing a Scrambled or a Caspase 8-targeting shRNA injected in SCID-bBeige mice. Representative pictures were taken at day 30 after injection. (C) End-stage tumor weight in mice injected with p95HER2/611CTF cells stably expressing either a Scrambled oligonucleotide or a Caspase-8-targeting shRNA $(n=8)$. Graphs shown mean \pm SEM. $* P<0.05$. (D) Representative images and quantification of CD31 $1^{+}$tumor vessel area in mice injected either with p95HER2shScr or p95HER2shCasp8 cells $(n=8)$. The vessel area was calculated by the percentage of CD31 area per field. 
apoptosis in p95HER2/611CTF cells we investigated the role of the eIF2 $\alpha$ kinases activated following ER stress or aminoacid deprivation, PERK and GCN2, respectively. Remarkably, we did not observe differences between mock and p95HER2/611CTF cells in the activation of eIF $2 \alpha$ kinases upon metabolic stress, as determined by the phosphorylation of the eukaryotic initiation factor $2 \alpha$ (eIF2 $\alpha$ ) (Supplementary Figure 5A). Furthermore, PERK silencing did not result in the inhibition of apoptosis following metabolic stress in p95HER2/611CTF cells (Supplementary Figure 5B). In contrast, PERK knockdown markedly reduced CAAT/enhancer binding protein homologous protein (CHOP) up-regulation and apoptosis induced by thapsigargin (Supplementary Figure 5B), a widely used activator of ER stress [22]. To further analyze the role of ER stress in the apoptotic response of p95HER2/611CTF cells to metabolic stress we silenced the expression of the other two UPR sensors of ER stress, Ire $1 \alpha$ and activating transcription factor-6 (ATF6), before incubating the cells in glutamine-free medium with 2DG. As shown in Supplementary Figure 5C, silencing of either Ire $1 \alpha$ or ATF 6 did not inhibit metabolic stress-induced apoptosis in p95HER2/611CTF cells, further excluding a role of the UPR in this cell death process.

The general control nonderepressible 2 (GCN2) signalling pathway is a major regulatory mechanisms for amino acid sensing that can play an adaptive role to sustain cell viability in response to glutamine deprivation [23]. However, GCN2 has been also involved in the apoptotic response of tumor cells to glutamine deprivation [24]. To investigate the role of the GCN2 pathway in metabolic stress-induced apoptosis in p95HER2/611CTF cells, GCN2 expression was silenced by siRNA interference prior to incubating the cells in starvation medium. Despite inhibiting CHOP induction upon glutamine deprivation, GCN2 knockdown failed to provide protection against starvation (Supplementary Figure 5D) thus excluding a proapoptotic role of the GCN2 pathway in p95HER2/611CTF cells subject to metabolic stress.

Ligand-independent assembly of the DISC has been demonstrated in the TNF family of death receptors, most likely due to the homotypic association of receptors mediated by the pre-ligand-binding assembly domain (PLAD) [25]. Moreover, the DISC components may colocalize in an intracellular membrane fraction in breast epithelial cells in the absence of TRAIL [26]. Furthermore, it was recently shown that ER stress activates a ligandindependent TRAIL-R2/DR5 multimerization in the Golgi apparatus leading to activation of the extrinsic apoptotic pathway [15]. Therefore, we investigated if metabolic stress-induced apoptosis in p95HER2/611CTF cells involved intracellular TRAIL-R2/DR5 clustering. We first examined co-localization of TRAIL-R2/DR5 with Golgi marker GM130 in starved cells or in cells treated with ER stress inducer thapsigargin. As shown in Figure 4A, TRAIL-R2/DR5 co-localized with GM130 in p95HER2/611CTF cells treated with thapsigargin, as previously demonstrated in other cell lines [15]. However, in contrast to the ER stress inducer, metabolic stress did not induce co-localization of TRAIL-R2/DR5 with the Golgi marker in p95HER2/611CTF cells (Figure 4A).

Generation of SDS-stable aggregates of TRAIL-R2/ DR5 is a requirement in the activation of caspase- 8 and apoptosis following TRAIL binding to this receptor [27]. To further investigate the role of TRAIL-R2/DR5 in the mechanism underlying ligand-independent apoptosis upon metabolic stress in p95HER2/611CTF cells we first determined by gel electrophoresis formation of SDSinsoluble aggregates at different times following metabolic stress. As shown in Figure 4B, SDS-stable aggregates were readily detected upon treatment of p95HER2/611CTF cells with 2DG in glutamine-free medium. Clustering of TRAIL receptors by TRAIL into high-molecular-weight complexes leads to DISC formation where caspase- 8 processing and activation takes place [27]. To determine whether metabolic stress induced ligand-independent DISC assembly at the cell surface, control or starved cells were incubated with biotin-labelled TRAIL (bio-TRAIL) at $4^{\circ} \mathrm{C}$ to facilitate loading of TRAIL receptors with bioTRAIL. At low temperature bio-TRAIL does not induce DISC assembly but it should allow the isolation of preformed DISC at the cell surface. Remarkably, results shown in Figure 4C demonstrate that metabolic stress induced DISC formation in p95HER2/611CTF cells but not in mock cells. If the different DISC formation between p95HER2/611CTF and mock cells is the result of the higher expression levels of TRAIL-R2/DR5 at the cell surface in p95HER2/611CTF cells is an issue that requires further investigation.

\section{FLIP is a master regulator of metabolic stress- induced apoptosis in p95HER2/611CTF- transformed cells}

When examining DISC assembly we observed an important loss of FLIP proteins specifically in cell lysates from p95HER2/611CTF cells upon metabolic stress (Figure 4C, lower panel). These results prompted us to investigate the role of FLIP in the enhanced sensitivity of p95HER2/611CTF cells to metabolic stress. Time course analysis of FLIP protein expression in both mock and p95HER2/611CTF cells incubated in glutamine-free medium with 2DG showed a marked down-regulation of both FLIP(L) and FLIP(S) levels in p95HER2/611CTF cells when compared with mock cells (Figure 5A). Proteasome-mediated degradation was involved in the loss of FLIP proteins in starved p95HER2/611CTF cells as it was prevented in the presence of the proteasome inhibitor MG132 (Figure 5B, left panel) but not by a lysosomal inhibitor (Figure 5B, right panel). Importantly, over-expression of FLIP(L) protein in p95HER2/611CTF cells significantly 
reduced apoptosis when these cells where incubated in glutamine-free medium with 2DG (Figure 5C), which supported a central role of FLIP in modulating the response to metabolic stress. Conversely, silencing FLIP(L) expression in mock MCF10A cells markedly sensitized these cells to metabolic stress (Figure 5D), further indicating that maintenance of cellular FLIP(L) levels plays a protective role in the apoptotic response to metabolic stress in human breast epithelial cells.

\section{mTOR activity governs metabolic stress-induced down-regulation of FLIP levels and apoptosis in p95HER2/611CTF-expressing cells}

Because of its ability to form homodimers maintained by disulphide bonds, p95HER2/611CTF is a constitutively active form of HER2 that activates multiple signalling pathways [5]. Amongst these, stimulation of the MAPK/Erk and PI3K/Akt pathways converges in the activation of the mTORC1 complex [28]. Deregulated activation of the mTORC1 complex leads to unrestrained protein synthesis and consequently to increased sensitivity to ER stress [29]. Likewise, in cells with mTOR over-activation, the maintenance of a high rate of protein synthesis under glucose deprivation leads to ATP depletion and cell death [9]. To determine the role of $\mathrm{mTORC} 1$ in the differential activation of apoptosis between mock and p95HER2/611CTF cells following metabolic stress, we first examined mTORC1 activity by measuring the phosphorylation state of the mTORC1 substrates p70S6K and 4E-BP1. Interestingly, whereas levels of phosphorylated $\mathrm{p} 70(\mathrm{~S} 6 \mathrm{~K})$ and $4 \mathrm{E}-\mathrm{BP} 1$ were
A
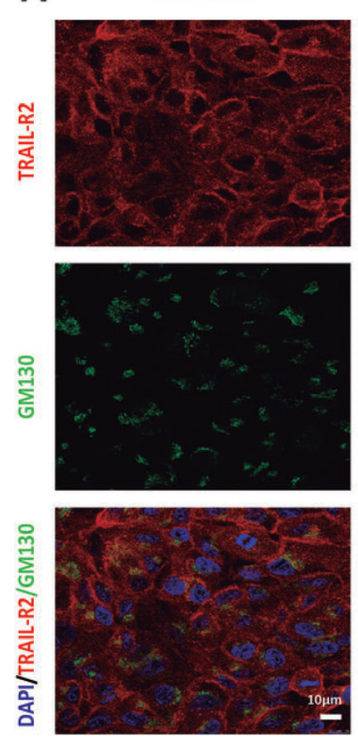

Starvation
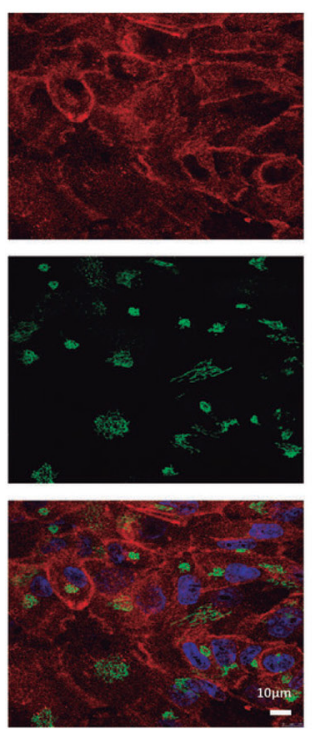

Thapsigargin
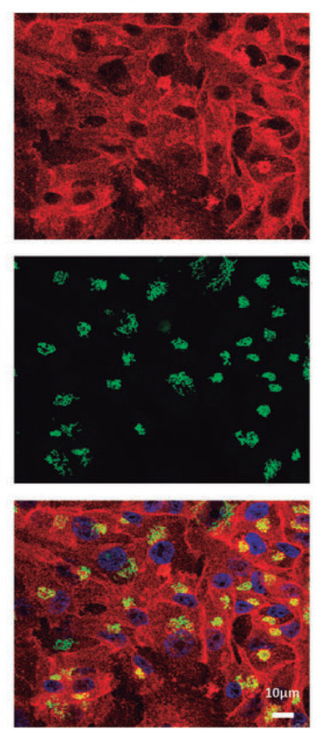

C

DISC
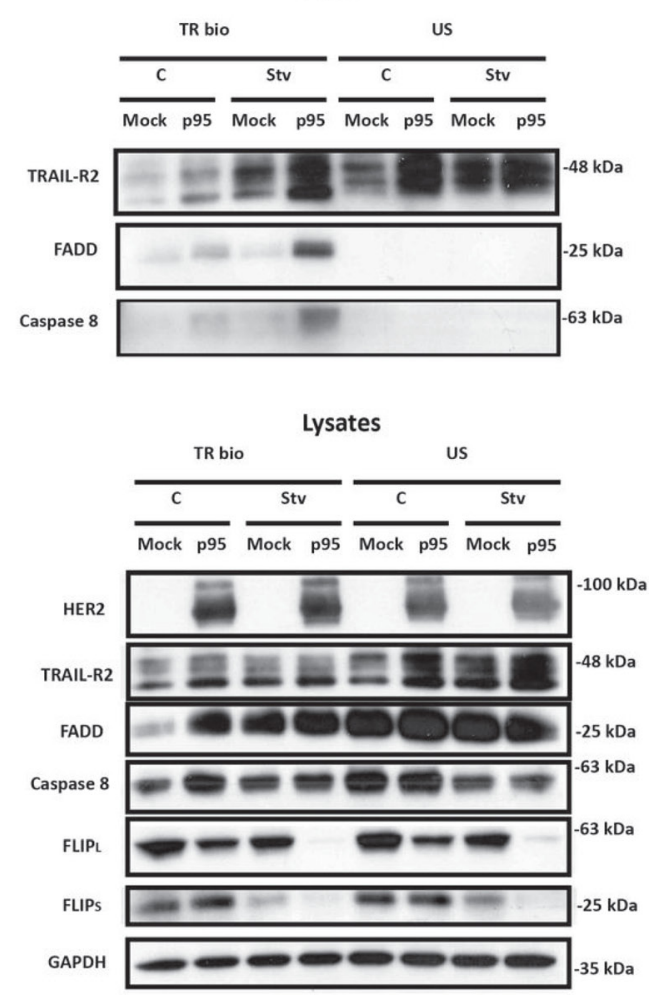
kDa

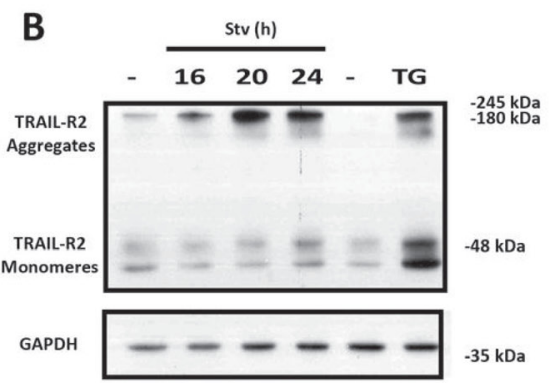

Figure 4: Metabolic stress induces TRAIL DISC formation at the plasma membrane in p95HER2/611CTF cells. (A) Confocal microscopy analysis of TRAIL-R2 distribution in p95HER2/611CTF cells either incubated in complete or starvation medium or treated with $100 \mathrm{nM}$ Thapsigargin for $21 \mathrm{~h}$, in the presence of Z-VAD $(20 \mu \mathrm{M})$. Merged images show labelling for DAPI, TRAIL-R2 and the Golgi Marker GM130. (B) p95HER2/611CTF cells were incubated either in complete or starvation medium for the indicated times, or treated with $100 \mathrm{nM}$ Thapsigargin for $16 \mathrm{~h}$ before collecting samples to determine TRAIL-R2 levels. (C) Mock or p95HER2/611CTF cells were cultured either in complete or starvation medium, in the presence of Q-VD $(20 \mu \mathrm{M})$ for $24 \mathrm{~h}$ prior to incubation on ice with bio-TRAIL $(1 \mu \mathrm{g} / \mathrm{ml})$ for $60 \mathrm{~min}$. Unstimulated receptor controls (US) represent the addition of bio-TRAIL to an equivalent volume of lysate isolated from cells kept on ice without bio-TRAIL. DISC isolation and analysis was performed as described in Materials and Methods (upper panel). Lower panel shows western blot analysis of proteins in cell lysates. Data shown are representative of 3 independent experiments. 
markedly reduced in mock cells upon metabolic stress, mTORC1 activity remained elevated for up to $16 \mathrm{~h}$ in p95HER2/611CTF cells (Figure 6A). Similar results were obtained when $\mathrm{Akt}^{\mathrm{Ser} 473}$ phosphorylation was determined to assess mTORC2 activity (Figure 6A). Altogether, these results suggest that deregulated activation of both mTOR complexes as a result of p95HER2/611CTF signalling makes these activities unresponsive to metabolic stress. We next examined the role of mTOR activation in metabolic stress-induced apoptosis by using torin1, a highly potent and selective ATP-competitive mTOR inhibitor which fully inhibits mTORC1 and mTORC2 complexes [30]. As shown in Figure 6B and Supplementary Figure 1D, right panel, torin 1 completely inhibited mTORC1 activities in p95HER2/611CTF cells. Furthermore, torin 1 also efficiently inhibited
mTORC2 activity as indicated by the complete inhibition of $\mathrm{Akt}^{\mathrm{Ser} 473}$ phosphorylation (Figure 6B, right panel and Supplementary Figure 1D). Strikingly, we observed a marked inhibition of starvation-induced apoptosis by torin 1 (Figure 6B and Supplementary Figure $1 \mathrm{D}$, left panels), suggesting an important role of mTOR in this cell death process. Interestingly, results shown in Figure 6B demonstrate that FLIP(L) and FLIP(S) down-regulation occurs in a mTOR-dependent manner as inhibition of mTOR by torin 1 significantly restored FLIP levels in p95HER2/611CTF cells.

The role of $\mathrm{mTORC} 1$ and $\mathrm{mTORC} 2$ activities in the sensitivity of p95HER2/611CTF-transformed cells to metabolic stress was further studied in experiments silencing Raptor or Rictor expression with a shRNA lentiviral vector. As shown in Figure 6C, Raptor
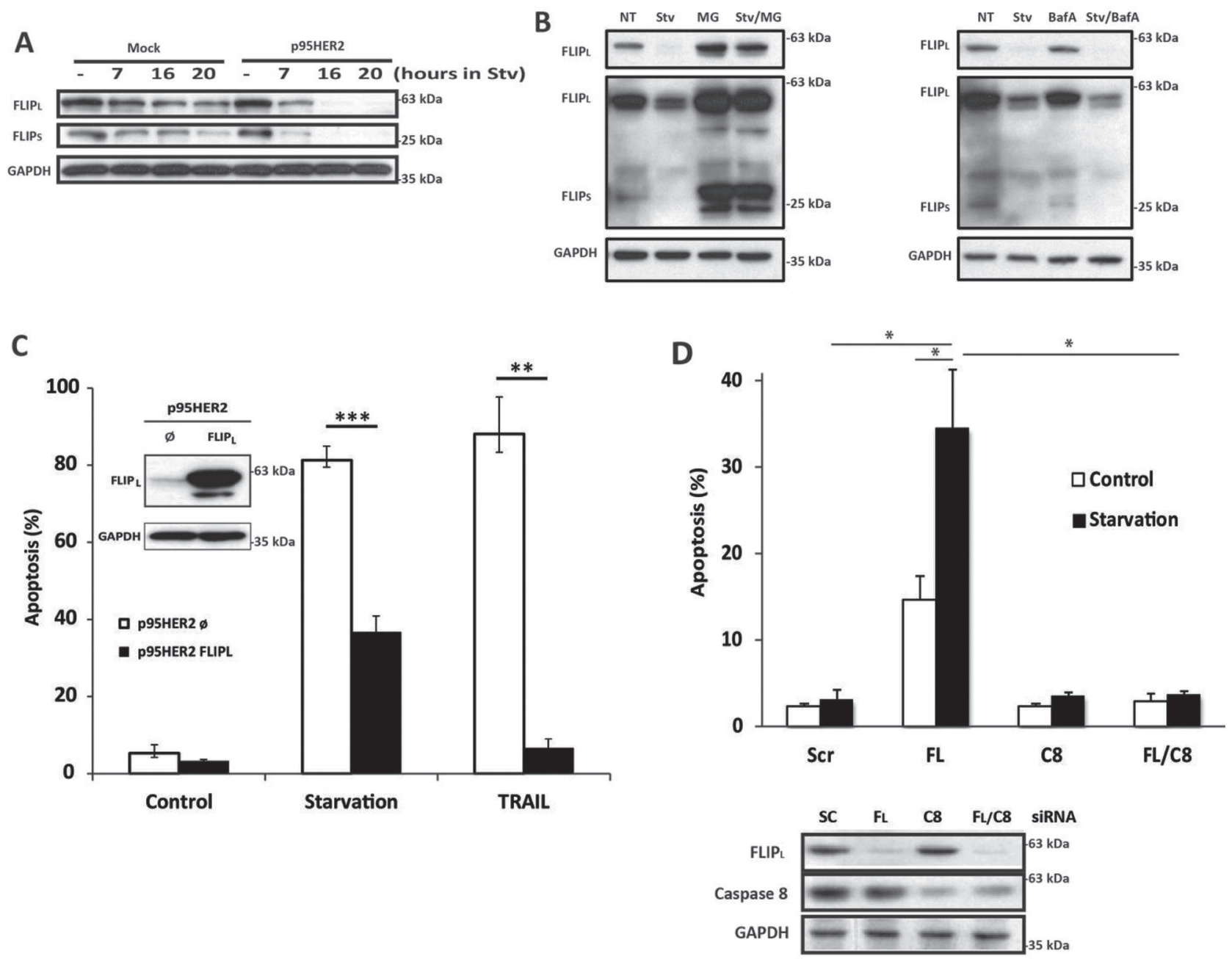

Figure 5: FLIP levels control cell death induced by metabolic stress. (A) FLIP levels in mock and p95HER2/611CTF cells cultured under starvation conditions. (B) FLIP levels in cells were cultured either in complete (NT) or Starvation medium for 16 h, in the presence or absence of $10 \mu \mathrm{M}$ MG132 (left panel) or $400 \mathrm{nM}$ Bafilomycin A (right panel). Results are representative of three independent experiments. (C) Apoptosis was assessed in FLIPL-overexpressing p95HER2/611CTF cells cultured in Stv or treated with TRAIL $(50 \mathrm{ng} / \mathrm{mL})$ for $30 \mathrm{~h}$. Insert shows FLIPL overexpression as measured by western-blotting. (D) Apoptosis in mock cells transfected for $16 \mathrm{~h}$ either with a Scrambled oligonucleotide or siRNAs targeting FLIPL, Caspase-8, or both and then cultured in complete or Stv medium for $6 \mathrm{~h}$ (upper panel). Protein knockdown was determined $16 \mathrm{~h}$ after transfection by western blotting (lower panel). Error bars, SD from three independent experiments. ${ }^{* * *} P<0.001, * * P<0.01, * P<0.05$. 
knockdown partially reduced the sensitivity of cells to glycolysis inhibition in glutamine-deprived medium, similarly to what is observed in cultures treated with rapamycin. Interestingly, silencing Rictor expression markedly inhibited FLIP down-regulation and apoptosis upon metabolic stress (Figure 6C), almost like the inhibition observed with Torin-1 (Figure 6B and 6C). Although both mTOR complexes seem to counteract the activation of apoptosis after metabolic stress, our results underscore the prominent role of $\mathrm{mTORC} 2$ activation as an effector of the signalling pathway leading to FLIP downregulation and apoptosis activation in p95HER2/611CTFtransformed cells undergoing metabolic stress.

\section{DISCUSSION}

Uncontrolled cell proliferation in tumors results in the development of aberrant vasculature in which the delivery of nutrients is drastically reduced leading to microenvironmental stress. To cope with this extrinsic form of stress, tumor cells must activate different adaptive responses [6]. However, different observations indicate that prior to adaptation oncogene-transformed cells may become very sensitive to nutrient deprivation and this represent a potential Achilles'heel in tumor progression [31-33].

Although MCF10A cells express markers not observed in mammary gland tissue [34] and show genetic abnormalities [35], they recapitulate many features of normal breast epithelium when grown in three-dimensional (3D) cultures, including the formation of growth-arrested polarized acini with a hollow lumen and basal deposition of basement membrane components [17]. Moreover, MCF10A cells and isogenic progression series have recently been used to identify driver genes associated with tumor progression from preinvasive to invasive cellular phenotypes as seen in primary breast cancer [19]. Interestingly, it has been demonstrated that Her2 activation in MCF10A cells initiates a sequence of events that is characteristic of neoplastic progression
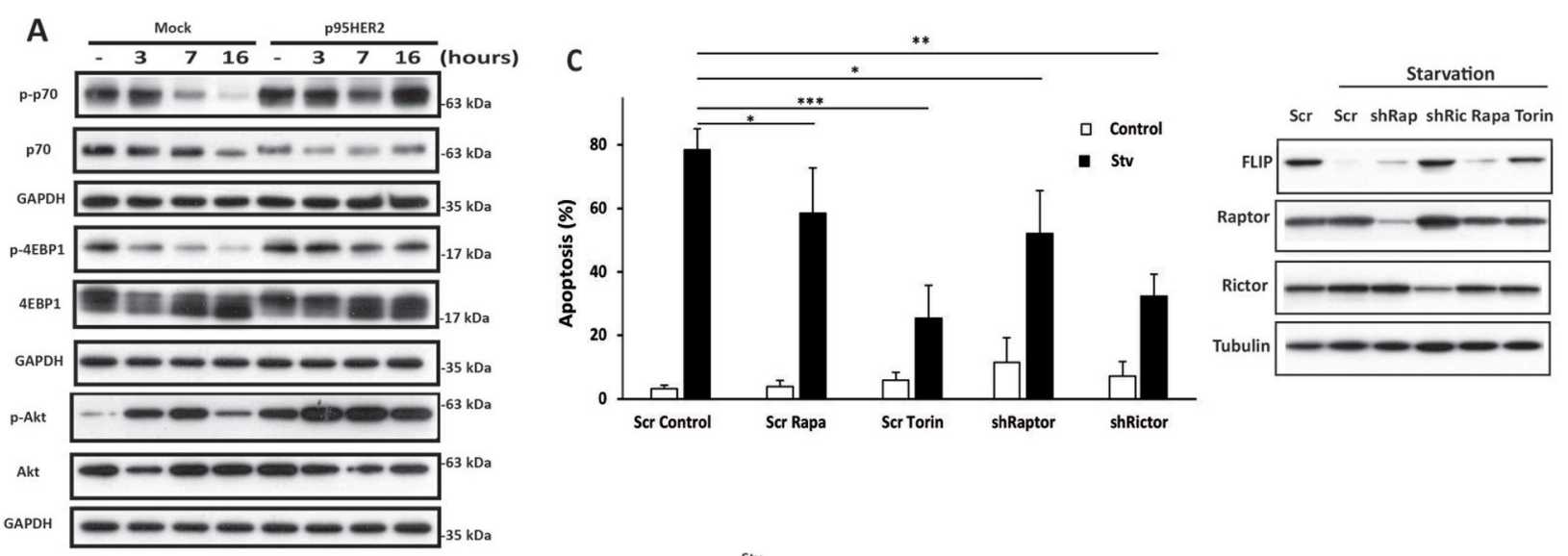

B
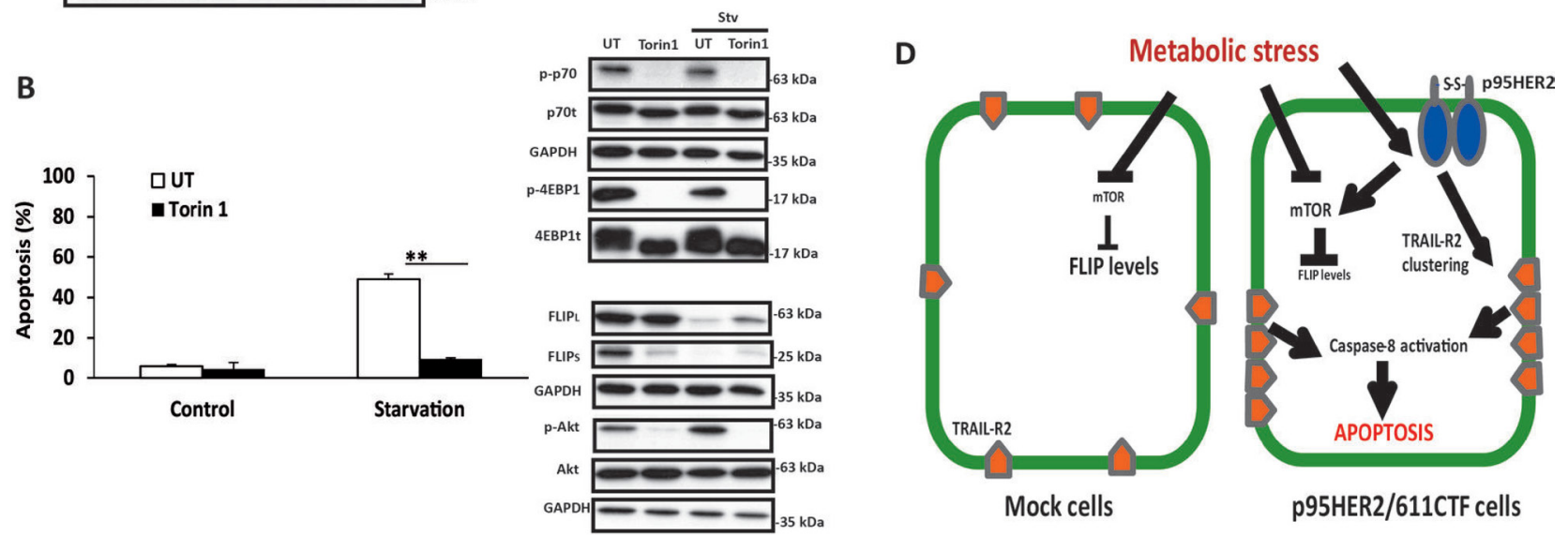

Figure 6: Role of mTOR complexes in apoptosis induced by metabolic stress. (A) Cells were cultured in Stv medium for the indicated times. Following these treatments, mTORC1 and mTORC2 activation (p-p70/S6K, p-4EBP1 and p-Akt ${ }^{\text {Ser473) }}$, was assessed by western blotting. Results are representative of 4 independent experiments. (B) Left panel shows apoptosis in p95HER2/611CTF cells cultured in complete or stv medium in the presence or absence of Torin-1 (250 nM). FLIP levels and mTORC1/mTORC2 activities were determined by western blot analysis (right panels). (C) Apoptosis in p95HER2/611CTF cells stably expressing a Scrambled, Raptor or Rictor shRNA cultured either in complete or stv medium (left panel). Where indicated, Rapamycin $(5 \mu \mathrm{M})$ or Torin $(250 \mathrm{nM})$ were added to the medium. Levels of FLIP, Raptor and Rictor proteins upon $16 \mathrm{~h}$ of treatment are shown in the right panel. Error bars, SD from three independent experiments. ${ }^{*} * P<0.001, * * P<0.01, * P<0.05$. (D) Schematic overview of the differential response to metabolic stress in control and p95HER2/611CTF cells. 
in early-stage epithelial tumours [18]. In our work we have investigated the response of human breast epithelial cells MCF10A transformed by the p95HER2/611CTF oncogene to metabolic stress. Our results demonstrate that p95HER2/611CTF-transformed cells are strikingly sensitive to the simultaneous inhibition of glucose and glutamine metabolism compared to untransformed cells or cells transformed with wild-type HER2. Differences in the activation levels of multiple signalling pathways and in the resulting transcriptome between wild-type HER2 and p95HER2/611CTF-transformed cells [5] may explain the strikingly different sensitivity to metabolic stress. Interestingly, p95HER2/611CTF expression in breast cancers or ectopic expression of p95HER2/611CTF in breast epithelial cells is associated to an increased rate of proliferation and marked sensitivity to different antitumor agents [36]. Likewise, expression of a constitutively active form of rat HER2 (NeuT) sensitizes human breast epithelial cells to genotoxic stress [37] and to agents that induce endoplasmic reticulum (ER) stress [14]. Together, these data suggest that constitutively active forms of HER2/ERBB2 may sensitize human breast epithelial cells to different stress-inducing conditions.

Our results clearly demonstrate a key role of caspase- 8 and pro-apoptotic TRAIL receptors in apoptosis induced upon metabolic stress in p95HER2/611CTFtransformed cells. Interestingly, TRAIL-R2/DR5 and caspase- 8 have been shown to participate in the apoptotic response induced following ER stress in different cell types $[14,15])$, through the formation of a TRAILindependent death-inducing signalling complex (DISC) in the Golgi apparatus [15]. However, our results demonstrate that in contrast to ER stress-mediated cell death, metabolic stress-induced apoptosis neither involves the activation of the unfolded protein response (UPR) pathways nor the accumulation of TRAIL-R2/DR5 in the Golgi apparatus. Instead, apoptosis induced by metabolic stress in p95HER2/611CTF-transformed cells requires TRAIL-independent DISC formation at the plasma membrane. In this regard, ligand-independent assembly of the DISC components has been described in death receptors of the TNF family, by the homotypic association of receptors through the pre-ligand-binding assembly domain (PLAD) [25]. Regarding TRAIL receptors, ectopic expression of TRAIL-R2/DR5 is sufficient to induce TRAIL-independent apoptosis [38]. Interestingly, our data show that $\mathrm{p} 95 \mathrm{HER} 2 / 611 \mathrm{CTF}$ expression increased TRAIL-R2/DR5 expression at the cell surface in breast epithelial cells. Moreover, TRAIL-R2/DR5 has been found to have a strong tendency to self-associate as a dimer which can be followed by the weak recruitment of a third monomer [39]. Whether or not nutrient starvation is stabilizing the trimeric form of TRAIL death receptors in p95HER2/611CTF-transformed cells is an important issue that warrants further investigation.
Constitutive activation of the intrinsic tyrosine kinase activity of p95HER2/611CTF leads to potent stimulation of signalling pathways MAPK/Erk and PI3K/ Akt among others, which are important for its enhanced oncogenic potential [5]. Some of the signalling pathways activated in p95HER2/611CTF-transformed cells are known to converge in mTORC1 activation [40]. Chronic activation of mTORC1 results in an increased sensitivity to ER stress [14, 29]. However, our data demonstrate that UPR signalling is not involved in the enhanced sensitivity of p95HER2/611CTF-transformed cells to metabolic stress. Likewise, metabolic stress may activate a GCN2/ eIF2 $\alpha /$ ATF4-dependent apoptotic pathway in cells with an elevated MEK1 activity [41]. Nevertheless, silencing GCN2 in p95HER2/611CTF-transformed cells did not abrogate metabolic stress-induced cell death. Collectively, our data indicate that signalling pathways activated by ER stress or amino acid deprivation are dispensable for apoptosis induced following metabolic stress in human breast epithelial cells transformed with p95HER2/611CTF.

A critical mechanism involved in regulating sensitivity to proapoptotic TRAIL receptor activation involves the modulation of $\mathrm{CFLIP}_{\mathrm{L}}$ and $\mathrm{CFLIP}_{\mathrm{S}}$ expression levels [13]. These are short-lived inhibitory proteins [42] that are expressed at high levels in breast cancers [43]. In breast cancer cells, selective suppression of FLIP expression by RNA interference induces caspase8-dependent apoptosis both in vitro and in vivo [44]. Collectively, our results reveal for the first time a key role of FLIP in the preservation of cell viability under metabolic stress in breast epithelial cells. Our data point at the deregulation of the mechanisms controlling the proteasomal degradation of FLIP [45] as an important step in the process leading to glycolysis and glutamine addiction in p95HER2/611CTF-transformed cells. A major finding of our study is that activity of the mTORC2 complex, in cooperation with mTORC1, is critically involved in the down-regulation of FLIP expression and apoptosis in starved p95HER2/611CTF-transformed cells. mTORC2 has been shown to increase c-Myc levels through the inactivation of class IIa histone deacetylases [46] and c-Myc is a transcriptional repressor of FLIP gene [47]. However, our results indicate that stability of FLIP proteins is most likely the mechanism involved in metabolic stress-induced FLIP down-regulation in p95HER2/611CTF-transformed cells. Moreover, our data not shown indicate the down-regulation of c-Myc protein expression following metabolic stress, further supporting a c-Myc-independent regulation of FLIP levels in p95HER2/611CTF-transformed cells. Unlike mTORC1 whose activity depends on the availability of amino acids [48], it has been recently demonstrated that mTORC2 is activated when glutamine levels become limited [49]. Furthermore, mTORC2 has been demonstrated previously to increase directly the stability of different kinases of the 
AGC kinase family via phosphorylation at a conserved turn motif [50]. On the contrary, phosphorylation by mTORC2 of ubiquitin ligase subunit Fbw8 enhances its stability allowing ubiquitination and degradation of mTORC1-phosphorylated insulin receptor substrate-1 (IRS-1) [51]. In this regard, further experiments are needed to characterize the mechanism by which FLIP proteins turnover is controlled in a concerted fashion by both mTOR complexes in p95HER2/611CTF-transformed cells undergoing nutrient deprivation.

In summary, we have identified in p95HER2/611CTFtransformed cells a cell death mechanism activated by metabolic stress that may be relevant in the initial sensitivity of early stage tumors to the nutrient deprivation conditions of the tumor microenvironment (Figure 6D). Our data suggest that at early stages of tumor growth, when p95HER2/611CTF-transformed cells start proliferating within the tumor, nutrient limitation and the likely increase in hypoxia would activate TRAIL-R/caspase- 8 system and cell death. Despite the initial sensitivity of tumor cells to the adverse conditions of the tumor microenvironment, activation of anti-apoptotic mechanisms and angiogenesis would allow tumor progression. In this respect, given the complexity of the human tumors, further studies in heterotypic in vitro models for tumor-stromal interactions are warranted to ascertain the impact of the tumor microenvironment in tumor cell fate decisions under nutrient limitation. In these models, deciphering the adaptive responses of tumor cells that may be involved in overcoming the apoptotic mechanism described in our work would reveal potential therapeutic targets.

\section{MATERIALS AND METHODS}

\section{Cell culture}

MCF10A, 184A1 and MCF10A-derived cell lines were maintained in DMEM/F12 medium supplemented with 5\% donor horse serum (Gibco), 2 mM L-glutamine, $20 \mathrm{ng} / \mathrm{ml}$ of epidermal growth factor (EGF), $10 \mu \mathrm{g} / \mathrm{ml}$ of insulin, $100 \mathrm{ng} / \mathrm{ml}$ of cholera toxin, $0.5 \mu \mathrm{g} / \mathrm{ml}$ of hydrocortisone, $5 \mu \mathrm{g} / \mathrm{ml}$ Transferrin (184A1), $50 \mathrm{U} / \mathrm{ml}$ of penicillin and $50 \mu \mathrm{g} / \mathrm{ml}$ of streptomycin. MDA-MB231 and HEK293-T cells were maintained in DMEM medium supplemented with $10 \%$ fetal bovine serum (Gibco), $2 \mathrm{mM}$ L-glutamine, $50 \mathrm{U}$ of penicillin $/ \mathrm{ml}$ and $50 \mu \mathrm{g}$ of streptomycin $/ \mathrm{ml}$. All cultures were incubated at $37^{\circ} \mathrm{C}$ in a $5 \% \mathrm{CO}_{2}$-humidified, $95 \%$ air incubator.

\section{Reagents and antibodies}

Media supplements and chemical reagents for molecular biology and buffer preparation were from Sigma-Aldrich, (St. Louis, MO, USA). Mouse antia-tubulin antibody, thapsigargin, human insulin, hydrocortisone, 2-deoxyglucose, DAPI (diamidino-2- phenylindole) and puromycin were obtained from SigmaAldrich. Anti-FADD, anti-GM130 antibodies and PEIgG Isotype control were obtained from BD Biosciences (Erembodegem, Belgium). Anti-human PE-TRAIL-R2 antibody was from Biolegend (San Diego, USA). Her2/ERBB2, pHer2 (Tyr 1248), p4E-BP1, 4E-BP1 and caspase- 8 antibodies were from Upstate Millipore (NY, USA). GAPDH and GCN2 antibodies were from Santa Cruz (CA, USA). Anti-TRAIL-R1 and anti-TRAIL-R2 were from R\&D Systems (Minneapolis, USA). Anti-cFLIP monoclonal antibodies NF6 and 7F10 were from Alexis Corporation (Lausen, Switzerland) and from Enzo Life Sciences (NY, USA), respectively. Anti p-AKT ${ }^{\text {Ser473, }}$ anti-AKT, anti-p-eIF2 $\alpha$, anti-eIF $2 \alpha$, anti-Ire $1 \alpha$, antip-P70S6K, anti-P70S6K, anti-PERK, anti-CHOP and anti-cleaved caspase- 8 antibodies were purchased from Cell Signalling Technology (CA, USA). Anti-p4EBP1 and anti-4E-BP1 antibodies were from UpstateMillipore (NY, USA). Horseradish peroxidase or FITCconjugated secondary antibodies were obtained from DAKO (Cambridge, UK). Cy3 or Alexa 488-conjugated secondary antibodies were from Jackson ImmunoResearch (Baltimore Pike, PA, USA). Human EGF was from Peprotech (London, UK). Recombinant human TRAIL was produced, and byotinilated as previously described [52]. Lapatinib and MG132, were purchased from Selleck Chemicals (Houston, Texas, USA). Q-VD was from AppexBio (Houston, USA). zVAD-fmk was from Bachem AG (Bachem, Bubendorf, Switzerland). Torin1 was purchased from TOCRIS Bioscience (Bristol, UK). Bafilomycin A was from LC Laboratories (MA, USA).

\section{Determination of apoptosis}

Cells $\left(3 \times 10^{5} /\right.$ well $)$ were treated in 6 -well plates as indicated in the figure legends. After treatment, hypodiploid apoptotic cells were detected by flow cytometry according to published procedures [53]. Apoptotic cells are expressed as percentage of the total cells counted.

\section{Immunoblot analysis of proteins}

Cells $\left(3 \times 10^{5}\right)$ were washed with phosphate-buffered saline (PBS) and lysed in TR3 buffer (10 mM Na2HPO4, $10 \%$ Glycerol, 3\% SDS). Protein content was measured with the Bradford reagent (Bio-Rad Laboratories, USA), before adding Laemmli sample buffer. Proteins were resolved on SDS-polyacrylamide minigels and detected as described previously [53]. Tubulin and GAPDH were used as protein loading controls.

\section{Real time-qPCR}

mRNA expression was analyzed in triplicate by RT-qPCR on the ABI Prism7500 sequence detection 
system using predesigned Assay-on-demand primers and probes (Applied Biosystems). Hypoxanthine-guanine phosphoribosyltransferase (HPRT1 Hs01003267_m1) was used as an internal control and mRNA expression levels of ATF6 and TRAIL were given as fraction of mRNA levels in control cells. Primers and probes used were: ATF6 (ATF6 Hs 00232586_m1) and TRAIL (TNFSF10 Hs00921974_m1).

\section{RNA interference}

siRNAs against TRAIL-R1, TRAIL-R2, TRAIL, Caspase-8, FLIP(L), PERK, GCN2, Ire1 $\alpha$, ATF6, and non-targeting scrambled oligonucleotide were synthesized by Sigma (St. Louis, MO, USA). Cells were transfected with siRNAs using DharmaFECT-1 (Dharmacon) as described by the manufacturer. After $6 \mathrm{~h}$, transfection medium was replaced with regular medium and cells were further incubated for $48 \mathrm{~h}$ before further analysis.

\section{siRNAs}

\begin{tabular}{|c|c|}
\hline $\begin{array}{l}\text { TRAIL-R1\#1 } \\
\text { TRAIL-R1\#2 }\end{array}$ & $\begin{array}{l}\text { 5'-GGAACUUUCCGGAAUGACAd } \\
\text { TdT-3' } \\
\text { 5'-CAGACUCGCUGUCCACUUU } \\
\text { dTdT-3' }\end{array}$ \\
\hline $\begin{array}{l}\text { TRAIL-R2\#1 } \\
\text { TRAIL-R2\#2 }\end{array}$ & $\begin{array}{l}\text { 5'-GACCCUUGUGCUCGUUGUCd } \\
\text { TdT-3' } \\
\text { 5'-UCAUGUAUCUAGAAGGUAUd } \\
\text { TdT-3' }\end{array}$ \\
\hline TRAIL: & $\begin{array}{l}\text { 5'-GAAUAUGGACUCUAUUCCAd } \\
\text { TdT-3' }\end{array}$ \\
\hline $\begin{array}{l}\text { Caspase-8\#1 } \\
\text { Caspase-8\#2 } \\
\text { Caspase-8\#3 }\end{array}$ & $\begin{array}{l}\text { 5'-GGAGCUGCUCUUCCCAAUUd } \\
\text { TdT-3' } \\
\text { 5'-GUUCCUGAGCCUGGACUACd } \\
\text { TdT-3' } \\
\text { 5'-AACUACCAGAAAGGUAUACC } \\
\text { UdTdT-3' }\end{array}$ \\
\hline FLIP $_{\mathrm{L}}:$ & $\begin{array}{l}\text { 5'-CCUAGGAAUCUGCCUGAUAdT }^{\prime} \\
\text { dT-3' }\end{array}$ \\
\hline PERK: & $\begin{array}{l}\text { 5'-CAAACUGUAUAACGGUUUAdT } \\
\text { dT-3' }\end{array}$ \\
\hline GCN2: & $\begin{array}{l}5^{\prime} \text {-CAGCAGAAAUCAUGUACGA } \\
\text { UU-3' }\end{array}$ \\
\hline IRE1 $\alpha$ : & $\begin{array}{l}\text { 5'-GCGUCUUUUACUACGUAAUdT } \\
\text { dT-3' }\end{array}$ \\
\hline ATF6: & $\begin{array}{l}5^{\prime}-\text { GCAACCAAUUAUCAGUUUAdT } \\
\text { dT-3' }\end{array}$ \\
\hline Scrambled: & $\begin{array}{l}\text { 5'-CUUUGGGUGAUCUACGUUAdT } \\
\text { dT-3' }\end{array}$ \\
\hline
\end{tabular}

Analysis of TRAIL receptors by flow cytometry

Cells were detached with trypsin solution and resuspended in growth media. After incubation for 15 minutes under cell culture conditions $\left(37^{\circ} \mathrm{C}\right.$ in a $5 \%$ $\mathrm{CO}_{2}$-humidified, $95 \%$ air incubator), cells were washed with ice-cold phosphate-buffered saline (PBS) and resuspended in PBS. Cells were then labelled either with $5 \mu \mathrm{g} / \mathrm{ml}$ of anti-TRAIL-R2-PE, antibody or an IgG-PE control antibody (BD Bioscience) for 30 minutes on ice and darkness. Analysis of the receptor cell surface expression was carried out in a FACSCalibur cytometer using the Cell Quest Software (Becton Dickinson, Mountain View, CA, USA).

\section{DISC isolation}

DISC precipitation was performed using biotintagged recombinant TRAIL (bio-TRAIL). Cells were cultured either in complete or starvation medium in the presence of Q-VD $(20 \mu \mathrm{M})$ for $24 \mathrm{~h}$. After this incubation, medium was replaced with ice-cold fresh medium, and cells incubated on ice with bio-TRAIL for 1 hour to allow loading of TRAIL-Rs with TRAIL [54]. Unbound TRAIL was then removed by washing the cells three times with ice-cold PBS and cells were lysed in $3 \mathrm{ml}$ of lysis buffer (30 mM Tris/ $\mathrm{HCl}$ pH 7.5, $150 \mathrm{mM} \mathrm{NaCl}, 10 \%$ glycerol, $1 \%$ Triton X-100) containing Complete Mini protease inhibitor cocktail tablets (Roche Molecular Biochemicals) for $30 \mathrm{~min}$ on ice followed by centrifugation at $15,000 \times \mathrm{g}$ for $30 \mathrm{~min}$ at $4^{\circ} \mathrm{C}$. To provide an unstimulated receptor control, bio-TRAIL was added to lysates from untreated cells. DISC was then precipitated from lysates containing the same amount of protein, using $30 \mu 1$ of streptavidinagarose beads at $4^{\circ} \mathrm{C}$ overnight. Precipitates were washed six times in lysis buffer, and receptor complexes were eluted with $30 \mu \mathrm{l}$ of sample buffer. Western blotting was performed as described above.

\section{Lentiviral and retroviral vectors}

HER2, p95HER2/611CTF and FLIP(L) retroviral vectors for stable gene expression have been described previously $[26,36]$. For silencing experiments, shRNAs against caspase-8, Raptor and Rictor in a pSUPER vector (OligoEngine) were digested and cloned between EcoR1 and Clal into a $\mathrm{H} 1$ promoter-driven GFP-encoding pLVTHM lentiviral vector [55]. Lentiviruses and retroviruses were produced by transfection of HEK293-T cells by the calcium phosphate method with the corresponding vectors. Lentivirus or retrovirus-containing supernatants were collected $48 \mathrm{~h}$ after transfection and concentrated by ultracentrifugation at $22,000 \mathrm{rpm}$ for 90 minutes at $4^{\circ} \mathrm{C}$. 


\section{Generation of MCF10A cell lines}

Stable populations of MCF10A and 184A1 cells infected with retroviruses were obtained after selection in culture medium containing puromycin $(1.5 \mu \mathrm{g} / \mathrm{ml})$ during $48 \mathrm{~h}$. MCF10A cells infected with GFP-expressing lentiviruses were detected by flow cytometry.

\section{Confocal microscopy analysis}

Cells were grown on coverslips and fixed in $4 \%$ paraformaldehyde for 10 minutes at RT and permeabilized with $0.5 \%$ Triton X-100. Then cells were incubated with primary antibodies for 1 hour at room temperature, washed with $0.1 \% \mathrm{PBS}$-Tween, and incubated with the appropriate fluorescent secondary antibody for 1 hour. Nuclei were stained with DAPI $(1 \mu \mathrm{g} / \mathrm{ml})$ after secondary labelling. Confocal images were captured using TCS SP5 confocal Leica laser scanning systems equipped with DMI60000 microscope. Image processing was carried out using the Leica (LAS) and Adobe Photoshop software. For presentation, whole images were adjusted for intensity level, contrast, and/ or brightness.

\section{Soft-agar colony formation assay}

To measure anchorage-independent growth, cells were detached with trypsin and resuspended in growth medium. Plates were prepared with a coating of $0,75 \%$ low melting agarose in growth medium and then overlaid with a suspension of cells in $0,45 \%$ low-melting agarose $\left(2.5 \times 10^{4}\right.$ cells $/$ well $)$. Plates were maintained for 26 days at $37^{\circ} \mathrm{C}$ in a $5 \% \mathrm{CO}_{2}$-humidified, $95 \%$ air incubator and the cells were fed with $200 \mu \mathrm{l}$ of growth media every 3 days. Colonies were stained with crystal violet at $0.01 \%$ in $\mathrm{H}_{2} 0$ with $10 \% \mathrm{EtOH}$, for 30 minutes.

\section{Acini formation in matrigel}

Morphogenesis assay were performed as previously described [56]. Briefly, mock, p95HER2/611CTF and MDA-MB231 cells were resuspended in assay medium (DMEM/F12 supplemented with $2 \%$ donor horse serum, $10 \mu \mathrm{g}$ of insulin $/ \mathrm{ml}, 100 \mathrm{ng}$ of cholera toxin $/ \mathrm{ml}, 0.5 \mu \mathrm{g}$ of hydrocortisone $/ \mathrm{ml}$, and $5 \mathrm{ng}$ of EGF/ml). Eight-well RS glass slides (BD Falcon) were coated with $40 \mu \mathrm{l}$ of Matrigel per well. Then, $5 \times 10^{3}$ cells were plated per well in assay medium containing a final concentration of $2 \%$ Matrigel. Assay medium containing 2\% Matrigel was replaced every 4 days.

\section{Animals}

SCID-bBeige (C.B-Igh-1b/GbmsTac-PrkdcscidLystbgN7) mice were purchased from Taconic. Housing and all experimental animal procedures were approved by the Institutional Animal Care and Research Advisory Committee of the K.U.Leuven (Belgium).

\section{Tumor model}

$10 \times 10^{6}$ cells MCF10A-p95shSCR or MCF10Ap95shCASP8 adherent growing human cells were injected subcutaneously at the right side of the mouse in a volume of $100 \mu \mathrm{l}$ of Matrigel diluted (1:1) in PBS. Tumor volumes were measured three times a week with a caliper and calculated using the formula: $\mathrm{V}=\pi \times\left(\mathrm{d}^{2} \times \mathrm{D}\right) / 6$, where $\mathrm{d}$ is the minor tumor axis and $\mathrm{D}$ is the major tumor axis. At the end stage, tumor weight was registered.

\section{Histology and immunostainings}

For serial sections cut at $7 \mu \mathrm{m}$ thickness, tumor samples were fixed in $2 \%$ PFA overnight at $4^{\circ} \mathrm{C}$, dehydrated and embedded in paraffin. Paraffin slides were first rehydrated to further proceed with antigen retrieval in citrate solution (DAKO). The sections were blocked with the appropriate serum (DAKO) and incubated overnight with rat anti-CD31 (BD Pharmingen) 1:200. Appropiate secondary antibodies were added with Hoescht 33342 (Life thechnologies). ProLong Gold mounting medium was used. Microscopic analysis was done with an Olympus BX41 microscope and CellSense imaging software.

\section{Statistical analysis}

All data are presented as the mean $\pm \mathrm{SE}$ of at least three independent experiments. The differences among different groups were determined by the Student's $t$ test. $P<0.05$ was considered significant. ${ }^{* * *} P<0.001$; $* * P<0.01 ; * P<0.05$.

\section{Abbreviations}

Stv, starvation; ER, endoplasmic reticulum; UPR, unfolded protein response; PERK, protein kinase RNA (PKR)-like ER kinase; Ire1 $\alpha$, inositol-requiring protein-1; ATF6, activating transcription factor-6; mTOR, mammalian target of rapamycin; CHOP, CAAT/enhancer binding protein homologous protein; TRAIL-R1, tumor necrosis factorrelated apoptosis-inducing ligand receptor 1; TRAIL-R2, tumor necrosis factor-related apoptosis-inducing ligand receptor 2; EGF, epidermal growth factor; EGFR, epidermal growth factor receptor; ERK, extracellular signal-regulated kinase; FLIP, FLICE-inhibitory protein; DISC, deathinducing signaling complex; 2DG, 2-Deoxy-D-Glucose; $\mathrm{SD}$, standard deviation.

\section{Author contributions}

RM-P, CP and AL-R, conceived ideas. RM-P, RY, MM, AL-R and CP, designed research. RM-P, RY, RM- 
$\mathrm{M}, \mathrm{AC}-\mathrm{G}$ and $\mathrm{CP}$, performed experiments. JA and MM, contributed materials. AL-R and CP, wrote the manuscript. All the authors analyzed data and reviewed the manuscript.

\section{ACKNOWLEDGMENTS}

We thank F.J. Fernandez-Farrán for excellent technical assistance.

\section{CONFLICTS OF INTEREST}

The authors disclose no potential conflicts of interest.

\section{FUNDING}

This work was supported by grants from Ministerio de Economía y Competitividad (SAF2012-32824 and SAF2015-64383-P), Junta de Andalucía Excellence Program (BIO 778), CIBERONC ISCIII CB16/12/00421 and Red Temática de Investigación Cooperativa en Cáncer (RD12/0036/0026 to ALR and RD12/0036/0042 to JA) and the European Community through the regional development funding program (FEDER).

\section{REFERENCES}

1. Slamon DJ, Clark GM, Wong SG, Levin WJ, Ullrich A, McGuire WL. Human breast cancer: correlation of relapse and survival with amplification of the HER-2/neu oncogene. Science. 1987; 235:177-182.

2. Arribas J, Baselga J, Pedersen K, Parra-Palau JL. p95HER2 and breast cancer. Cancer Res. 2011; 71:1515-1519.

3. Anido J, Scaltriti M, Bech Serra JJ, Santiago Josefat B, Todo FR, Baselga J, Arribas J. Biosynthesis of tumorigenic HER2 C-terminal fragments by alternative initiation of translation. EMBO J. 2006; 25:3234-3244.

4. Scaltriti M, Rojo F, Ocana A, Anido J, Guzman M, Cortes J, Di Cosimo S, Matias-Guiu X, Ramon y Cajal S, Arribas J, Baselga J. Expression of p95HER2, a truncated form of the HER2 receptor, and response to anti-HER2 therapies in breast cancer. J Natl Cancer Inst. 2007; 99:628-638.

5. Pedersen K, Angelini PD, Laos S, Bach-Faig A, Cunningham MP, Ferrer-Ramon C, Luque-Garcia A, Garcia-Castillo J, Parra-Palau JL, Scaltriti M, Ramon y Cajal S, Baselga J, Arribas J. A naturally occurring HER2 carboxy-terminal fragment promotes mammary tumor growth and metastasis. Mol Cell Biol. 2009; 29:3319-3331.

6. Pavlova NN, Thompson CB. The Emerging Hallmarks of Cancer Metabolism. Cell Metab. 2016; 23:27-47.

7. Warburg O. On the origin of cancer cells. Science. 1956; 123:309-314.

8. DeBerardinis RJ, Cheng T. Q's next: the diverse functions of glutamine in metabolism, cell biology and cancer. Oncogene. 2010; 29:313-324.
9. Choo AY, Kim SG, Vander Heiden MG, Mahoney SJ, Vu H, Yoon SO, Cantley LC, Blenis J. Glucose addiction of TSC null cells is caused by failed mTORC1-dependent balancing of metabolic demand with supply. Mol Cell. 2010; 38:487-499.

10. Qing G, Li B, Vu A, Skuli N, Walton ZE, Liu X, Mayes PA, Wise DR, Thompson CB, Maris JM, Hogarty MD, Simon MC. ATF4 regulates MYC-mediated neuroblastoma cell death upon glutamine deprivation. Cancer Cell. 2012; 22: 631-644.

11. Ashkenazi A, Dixit VM. Death receptors: signaling and modulation. Science. 1998; 281:1305-1308.

12. Sprick MR, Weigand MA, Rieser E, Rauch CT, Juo P, Blenis J, Krammer PH, Walczak H. FADD/MORT1 and caspase- 8 are recruited to TRAIL receptors 1 and 2 and are essential for apoptosis mediated by TRAIL receptor 2 . Immunity. 2000; 12:599-609.

13. Irmler M, Thome M, Hahne M, Schneider P, Hofmann K, Steiner V, Bodmer JL, Schroter M, Burns K, Mattmann C, Rimoldi D, French LE, Tschopp J. Inhibition of death receptor signals by cellular FLIP. Nature. 1997; 388: 190-195.

14. Martin-Perez R, Palacios C, Yerbes R, Cano-Gonzalez A, Iglesias-Serret D, Gil J, Reginato MJ, Lopez-Rivas A. Activated ERBB2/HER2 licenses sensitivity to apoptosis upon endoplasmic reticulum stress through a PERKdependent pathway. Cancer Res. 2014; 74:1766-1777.

15. Lu M, Lawrence DA, Marsters S, Acosta-Alvear D, Kimmig P, Mendez AS, Paton AW, Paton JC, Walter P, Ashkenazi A. Opposing unfolded-protein-response signals converge on death receptor 5 to control apoptosis. Science. 2014; 345:98-101.

16. Kline CL, Van den Heuvel AP, Allen JE, Prabhu VV, Dicker DT, El-Deiry WS. ONC201 kills solid tumor cells by triggering an integrated stress response dependent on ATF4 activation by specific eIF2alpha kinases. Sci Signal. 2016; 9:ra18.

17. Debnath J, Brugge JS. Modelling glandular epithelial cancers in three-dimensional cultures. Nat Rev Cancer. 2005; 5:675-688.

18. Leung CT, Brugge JS. Outgrowth of single oncogeneexpressing cells from suppressive epithelial environments. Nature. 2012; 482:410-413.

19. Maguire SL, Peck B, Wai PT, Campbell J, Barker H, Gulati A, Daley F, Vyse S, Huang P, Lord CJ, Farnie G, Brennan K, Natrajan R. Three-dimensional modelling identifies novel genetic dependencies associated with breast cancer progression in the isogenic MCF10 model. J Pathol. 2016; 240:315-328.

20. Ackerman D, Simon MC. Hypoxia, lipids, and cancer: surviving the harsh tumor microenvironment. Trends Cell Biol. 2014; 24:472-478.

21. Donnelly N, Gorman AM, Gupta S, Samali A. The eIF2alpha kinases: their structures and functions. Cell Mol Life Sci. 2013; 70:3493-3511. 
22. Walter P, Ron D. The unfolded protein response: from stress pathway to homeostatic regulation. Science. 2011; 334:1081-1086.

23. Ye J, Palm W, Peng M, King B, Lindsten T, Li MO, Koumenis C, Thompson CB. GCN2 sustains mTORC1 suppression upon amino acid deprivation by inducing Sestrin2. Genes Dev. 2015; 29:2331-2336.

24. Drogat B, Bouchecareilh M, North S, Petibois C, Deleris G, Chevet E, Bikfalvi A, Moenner M. Acute L-glutamine deprivation compromises VEGF-a upregulation in A549/8 human carcinoma cells. J Cell Physiol. 2007; 212:463-472.

25. Chan FK, Chun HJ, Zheng L, Siegel RM, Bui KL, Lenardo MJ. A domain in TNF receptors that mediates ligandindependent receptor assembly and signaling. Science. 2000; 288:2351-2354.

26. Yerbes R, Palacios C, Reginato MJ, Lopez-Rivas A. Cellular FLIP(L) plays a survival role and regulates morphogenesis in breast epithelial cells. Biochim Biophys Acta. 2011; 1813:168-178.

27. Wagner KW, Punnoose EA, Januario T, Lawrence DA, Pitti RM, Lancaster K, Lee D, von Goetz M, Yee SF, Totpal K, Huw L, Katta V, Cavet G, et al. Death-receptor O-glycosylation controls tumor-cell sensitivity to the proapoptotic ligand Apo2L/TRAIL. Nat Med. 2007; 13:1070-1077.

28. Gao B, Roux PP. Translational control by oncogenic signaling pathways. Biochim Biophys Acta. 2015; 1849:753-765.

29. Ozcan U, Ozcan L, YilmazE, Duvel K, Sahin M, Manning BD, Hotamisligil GS. Loss of the tuberous sclerosis complex tumor suppressors triggers the unfolded protein response to regulate insulin signaling and apoptosis. Mol Cell. 2008; 29:541-551.

30. Thoreen CC, Kang SA, Chang JW, Liu Q, Zhang J, Gao Y, Reichling LJ, Sim T, Sabatini DM, Gray NS. An ATPcompetitive mammalian target of rapamycin inhibitor reveals rapamycin-resistant functions of $\mathrm{mTORC1}$. J Biol Chem. 2009; 284:8023-8032.

31. Elstrom RL, Bauer DE, Buzzai M, Karnauskas R, Harris MH, Plas DR, Zhuang H, Cinalli RM, Alavi A, Rudin CM, Thompson CB. Akt stimulates aerobic glycolysis in cancer cells. Cancer Res. 2004; 64:3892-3899.

32. Wise DR, DeBerardinis RJ, Mancuso A, Sayed N, Zhang XY, Pfeiffer HK, Nissim I, Daikhin E, Yudkoff M, McMahon SB, Thompson $\mathrm{CB}$. Myc regulates a transcriptional program that stimulates mitochondrial glutaminolysis and leads to glutamine addiction. Proc Natl Acad Sci USA. 2008; 105:18782-18787.

33. Leprivier G, Sorensen PH. How does oncogene transformation render tumor cells hypersensitive to nutrient deprivation? BioEssays. 2014; 36:1082-1090.

34. Qu Y, Han B, Yu Y, Yao W, Bose S, Karlan BY, Giuliano AE, Cui X. Evaluation of MCF10A as a Reliable Model for Normal Human Mammary Epithelial Cells. PLoS One. 2015; 10:e0131285.
35. Kietzman W. RAVOV. Early-Stage Progression of Breast Cancer. In: Pham PV, editor. Breast Cancer - From Biology to Medicine: InTech). 2017.

36. Parra-Palau JL, Morancho B, Peg V, Escorihuela M, Scaltriti M, Vicario R, Zacarias-Fluck M, Pedersen K, Pandiella A, Nuciforo P, Serra V, Cortes J, Baselga J, et al. Effect of p95HER2/611CTF on the response to trastuzumab and chemotherapy. J Natl Cancer Inst. 2014; 106.

37. Sherman MY, Meng L, Stampfer M, Gabai VL, Yaglom JA. Oncogenes induce senescence with incomplete growth arrest and suppress the DNA damage response in immortalized cells. Aging Cell. 2011; 10:949-961.

38. Sheridan JP, Marsters SA, Pitti RM, Gurney A, Skubatch M, Baldwin D, Ramakrishnan L, Gray CL, Baker K, Wood WI, Goddard AD, Godowski P, Ashkenazi A. Control of TRAILinduced apoptosis by a family of signaling and decoy receptors. Science. 1997; 277:818-821.

39. Wassenaar TA, Quax WJ, Mark AE. The conformation of the extracellular binding domain of Death Receptor 5 in the presence and absence of the activating ligand TRAIL: a molecular dynamics study. Proteins. 2008; 70:333-343.

40. Sengupta S, Peterson TR, Sabatini DM. Regulation of the mTOR complex 1 pathway by nutrients, growth factors, and stress. Mol Cell. 2010; 40:310-322.

41. Shin S, Buel GR, Wolgamott L, Plas DR, Asara JM, Blenis J, Yoon SO. ERK2 Mediates Metabolic Stress Response to Regulate Cell Fate. Mol Cell. 2015; 59:382-398.

42. Fukazawa T, Fujiwara T, Uno F, Teraishi F, Kadowaki Y, Itoshima T, Takata Y, Kagawa S, Roth JA, Tschopp J, Tanaka N. Accelerated degradation of cellular FLIP protein through the ubiquitin-proteasome pathway in p53-mediated apoptosis of human cancer cells. Oncogene. 2001; 20:5225-5231.

43. Conticello C, Pedini F, Zeuner A, Patti M, Zerilli M, Stassi G, Messina A, Peschle C, De Maria R. IL-4 protects tumor cells from anti-CD95 and chemotherapeutic agents via up-regulation of antiapoptotic proteins. J Immunol. 2004; 172:5467-5477.

44. Day TW, Sinn AL, Huang S, Pollok KE, Sandusky GE, Safa AR. c-FLIP gene silencing eliminates tumor cells in breast cancer xenografts without affecting stromal cells. Anticancer Res. 2009; 29:3883-3886.

45. Tsuchiya Y, Nakabayashi O, Nakano H. FLIP the Switch: Regulation of Apoptosis and Necroptosis by cFLIP. Int $\mathrm{J}$ Mol Sci. 2015; 16:30321-30341.

46. Masui K, Tanaka K, Akhavan D, Babic I, Gini B, Matsutani T, Iwanami A, Liu F, Villa GR, Gu Y, Campos C, Zhu S, Yang H, et al. mTOR complex 2 controls glycolytic metabolism in glioblastoma through FoxO acetylation and upregulation of c-Myc. Cell Metab. 2013; 18:726-739.

47. Ricci MS, Jin Z, Dews M, Yu D, Thomas-Tikhonenko A, Dicker DT, El-Deiry WS. Direct repression of FLIP expression by c-myc is a major determinant of TRAIL sensitivity. Mol Cell Biol. 2004; 24:8541-8555. 
48. Bar-Peled L, Sabatini DM. Regulation of mTORC1 by amino acids. Trends Cell Biol. 2014; 24:400-406.

49. Moloughney JG, Kim PK, Vega-Cotto NM, Wu CC, Zhang S, Adlam M, Lynch T, Chou PC, Rabinowitz JD, Werlen G, Jacinto E. mTORC2 Responds to Glutamine Catabolite Levels to Modulate the Hexosamine Biosynthesis Enzyme GFAT1. Mol Cell. 2016; 63:811-826.

50. Facchinetti V, Ouyang W, Wei H, Soto N, Lazorchak A, Gould C, Lowry C, Newton AC, Mao Y, Miao RQ, Sessa WC, Qin J, Zhang P, et al. The mammalian target of rapamycin complex 2 controls folding and stability of Akt and protein kinase C. EMBO J. 2008; 27:1932-1943.

51. Kim SJ, DeStefano MA, Oh WJ, Wu CC, Vega-Cotto NM, Finlan M, Liu D, Su B, Jacinto E. mTOR complex 2 regulates proper turnover of insulin receptor substrate-1 via the ubiquitin ligase subunit Fbw8. Mol Cell. 2012; 48:875-887.

52. Harper N, Farrow SN, Kaptein A, Cohen GM, MacFarlane M. Modulation of tumor necrosis factor apoptosis-inducing ligand- induced NF-kappa B activation by inhibition of apical caspases. J Biol Chem. 2001; 276:34743-34752.
53. Yerbes R, Lopez-Rivas A, Reginato MJ, Palacios C. Control of FLIP(L) expression and TRAIL resistance by the extracellular signal-regulated kinase $1 / 2$ pathway in breast epithelial cells. Cell Death Differ. 2012; 19:1908-1916.

54. Hughes MA, Langlais C, Cain K, MacFarlane M. Isolation, characterisation and reconstitution of cell death signalling complexes. Methods. 2013; 61:98-104.

55. Wiznerowicz M, Trono D. Conditional suppression of cellular genes: lentivirus vector-mediated drug-inducible RNA interference. J Virol. 2003; 77:8957-8961.

56. Muthuswamy SK, Li D, Lelievre S, Bissell MJ, Brugge JS. ErbB2, but not ErbB1, reinitiates proliferation and induces luminal repopulation in epithelial acini. Nat Cell Biol. 2001; $3: 785-792$ 